\title{
Glia Induce Dendritic Growth in Cultured Sympathetic Neurons by Modulating the Balance between Bone Morphogenetic Proteins (BMPs) and BMP Antagonists
}

\author{
Pamela J. Lein, ${ }^{1}$ Hiroko Nagasawa Beck, ${ }^{1}$ Vidya Chandrasekaran, ${ }^{2}$ Patrick J. Gallagher, ${ }^{3}$ Hui-Ling Chen, ${ }^{1,4}$ \\ Yuan Lin, ${ }^{5}$ Xin Guo, ${ }^{1}$ Paul L. Kaplan, ${ }^{6}$ Henri Tiedge, ${ }^{5}$ and Dennis Higgins ${ }^{2}$ \\ ${ }^{1}$ Department of Environmental Health Sciences, Johns Hopkins University Bloomberg School of Public Health, Baltimore, \\ Maryland 21205, 2Department of Pharmacology and Toxicology, State University of New York, Buffalo, New York 14214, \\ ${ }^{3}$ Department of Biology, Canisius College, Buffalo, New York 14208, ${ }^{4}$ Graduate Institute of Life Sciences, National \\ Defense Medical Center, National Defense University, Taipei, Taiwan, ${ }^{5}$ Department of Physiology and Pharmacology, State \\ University of New York, Brooklyn, New York 11203, and ${ }^{6}$ Creative Biomolecules, Inc., Hopkinton, Massachusetts 01748
}

Dendritic growth in cultured sympathetic neurons requires specific trophic interactions. Previous studies have demonstrated that either coculture with glia or exposure to recombinant bone morphogenetic proteins (BMPs) is both necessary and sufficient to induce dendrite formation. These observations led us to test the hypothesis that BMPs mediate glial-induced dendritic growth. In situ hybridization and immunocytochemical studies indicate that the spatiotemporal expression of BMP5, -6 , and -7 in rat superior cervical ganglia (SCG) is consistent with their proposed role in dendritogenesis. In vitro, both SCG glia and neurons were found to express BMP mRNA and protein when grown in the presence or absence of the other cell type. How- ever, addition of ganglionic glia to cultured sympathetic neurons causes a marked increase in BMP proteins coincident with a significant decrease in follistatin and noggin. Functional assays indicate that glial-induced dendritic growth is significantly reduced by BMP7 antibodies and completely inhibited by exogenous noggin and follistatin. These data suggest that glia influence the rapid perinatal expansion of the dendritic arbor in sympathetic neurons by increasing BMP activity via modulation of the balance between BMPs and their antagonists.

Key words: BMPs; BMP antagonists; noggin; follistatin; dendrites; sympathetic neurons; neuron-glia interactions
Reciprocal interactions between neurons and glia are critical to the development of the nervous system (Hatten, 1990; Pfrieger and Barres, 1996; Barres, 1999). One aspect of neuronal development modulated by glia is dendritic growth. Thus, sympathetic neurons grown in the absence of glia extend a single process, which is axonal. In contrast, coculture with glia causes these neurons to form a dendritic arbor comparable with that observed in situ (Tropea et al., 1988). Glial stimulation of dendritic growth has also been observed in cultured striatal, mesencephalic, cerebral cortical, retinal ganglion, and preganglionic sympathetic neurons (for review, see Higgins et al., 1997), suggesting that it may be a fairly common mechanism for determining neuronal shape. This hypothesis is supported by demonstration that deleting the glial cells missing gene in Drosophila results in failed glial devel-

Received May 8, 2002; revised Sept. 13, 2002; accepted Sept. 26, 2002.

This work was supported by National Institutes of Health (NIH)/National Institute of Neurological Disorders and Stroke Grant 1 R15 NS/OD36401-01 (P.L.), $\mathrm{NIH} /$ National Institute of Environmental Health Sciences Grant 2 P30 ES03819-14 (P.L.), National Science Foundation Grant IBN 9808565 (D.H.), NIH Grant RO1 NS34158 (H.T.), and a grant to Canisius College from the Howard Hughes Medical Institute through the Undergraduate Science Program (H.N.B., P.J.G.). We thank Dr. Ruben Adler (Johns Hopkins University) for suggestions regarding experimentation and constructive criticism of the text; Ann Marie Hedges and James DiFrancesco (Canisius College) for technical assistance; Ilham Muslimov (State University of New York at Brooklyn) for technical advice regarding in situ hybridization; and Brian Schofield (Johns Hopkins University) for help with photomicroscopy and imaging.

Correspondence should be addressed to Pamela Lein, Department of Environmental Health Sciences, Johns Hopkins University Bloomberg School of Public Health, 615 North Wolfe Street, Baltimore, MD 21205-2179. E-mail: plein@jhsph.edu.

Copyright $(\odot 2002$ Society for Neuroscience $0270-6474 / 02 / 2210377-11 \$ 15.00 / 0$ opment coincident with lack of dendrite formation by otherwise differentiated bipolar dendrite neurons (Jones et al., 1995).

The molecular mechanisms by which glia induce dendritic growth are not well characterized. Progress has been made in identifying molecules that selectively stimulate dendritic growth (Higgins et al., 1997; Calvet et al., 1998; Vaillant et al., 1999); of particular interest are bone morphogenetic proteins (BMPs), which are members of the TGF- $\beta$ superfamily. The developing nervous system expresses multiple BMPs, including BMP5, -6, and -7 of the 60A subgroup, BMP2 and -4 of the dpp subgroup, and dorsalin and GDF-1 of the dorsalin subgroup (for review, see Lein et al., 2002). In vitro studies have demonstrated that BMP2, $-5,-6$, and -7 , but not dorsalin, activin, TGF- $\beta 1$, or GDNF, cause sympathetic neurons to form processes that express the morphological, cytoskeletal, and ultrastructural properties of dendrites (Lein et al., 1995; Guo et al., 1998; Beck et al., 2001). BMPs also selectively enhance dendritic growth in cultured hippocampal (Withers et al., 2000), cerebral cortical (Le Roux et al., 1999), and striatal neurons (Gratacos et al., 2001). BMPs are expressed in at least some glial cell populations, including radial glial cells in the developing and adult CNS (Schluesener and Meyermann, 1994; Jordan et al., 1997) and Schwann cells in adult sciatic nerve (Schluesener et al., 1995). However, a functional relationship between glial-induced dendritic growth and glial expression of BMPs has not been explored.

BMP signaling is determined by expression patterns of BMPs, their receptors, and soluble BMP antagonists, such as noggin and follistatin, which directly bind BMPs and prevent functional receptor/ligand interaction (for review, see Cho and Blitz, 1998). 
It has been reported that BMP receptors are expressed in developing sympathetic ganglia (Zhang et al., 1998). Thus, as a first test of the hypothesis that BMPs mediate glial-induced dendritic growth, we examined BMP, noggin, and follistatin expression in superior cervical ganglia (SCG) neurons and glia. To assess the function of BMPs in glial-induced dendritic growth, we interfered with BMP activity in neuron-glia cocultures using function-blocking BMP antibodies or recombinant BMP antagonists. Our data indicate that glial-induced dendritic growth is mediated by increased BMP activity resulting from simultaneous upregulation of BMP levels and downregulation of noggin and follistatin levels. Thus, glia regulate dendritic growth by modulating the relative balance between BMPs and BMP antagonists.

\section{MATERIALS AND METHODS}

Materials. Purified human recombinant BMPs (2, 4, 5, 6, and 7) were provided by Creative Biomolecules (now Curis, Cambridge, MA). Affinity-purified polyclonal antibody (Ab) specific for BMP2, -4, -5, and -6 and their corresponding blocking peptides were purchased from Research Diagnostics (Flanders, NJ). The specificity of these antibodies was confirmed via Western blot analyses demonstrating that these antibodies did not cross-react with inappropriate BMP family members and that blocking peptide inhibited binding to the appropriate recombinant BMP. Two different monoclonal antibodies (mAbs), 12G3 and 1B12, which react with different epitopes on the BMP7 molecule (W. K. Jones, Creative Biomolecules/Curis, personal communication), and polyclonal $\mathrm{Ab}$ raised against recombinant human BMP7 were generous gifts from Creative Biomolecules (Curis). It has been demonstrated that neither mAb cross-reacts with BMP2 or -4 (Vukicevic et al., 1994). Both mAbs were tested in all function-blocking and immunocytochemistry experiments described in Results and were found to yield comparable results. The polyclonal BMP7 Ab, which was used for Western blot analysis, did not cross-react to any significant extent with recombinant BMP2, $-4,-5$, or -6. Xenopus noggin protein (Lamb et al., 1993) was the generous gift of Drs. José de Jesús and Richard Harland (University of California at Berkeley). Regeneron Pharmaceuticals generously provided rat mAb RP57-16 to human noggin. There is only one amino acid change between human and rodent noggin (McMahon et al., 1998), and this amino acid does not lie within the region recognized by mAb RP57-16. Recombinant human follistatin (B4384) was obtained through the National Hormone and Pituitary Program, National Institute of Diabetes and Digestive and Kidney Diseases via Dr. A. F. Parlow (Torrance, CA); mouse antihuman follistatin $\mathrm{mAb}$ was purchased from R \& D Systems (Minneapolis, MN). Antibody that recognizes Smad-1 was purchased from Upstate Biotechnology (Lake Placid, NY).

Tissue culture. Sympathetic neurons were dissociated from the SCG of embryonic day 21 (E21) or postnatal day 1-2 (PN1-2) Holtzmann rats (Harlan Sprague Dawley, Rockford, IL) according to previously described methods (Higgins et al., 1991). Cells were plated onto one of two different substrates: (1) glass coverslips or $35 \mathrm{~mm}$ plastic culture dishes first precoated with poly-D-lysine at $100 \mu \mathrm{g} / \mathrm{ml}$ (Sigma, St. Louis, MO) and then with collagen IV at $100 \mu \mathrm{g} / \mathrm{ml}$ (Collaborative Biomedical Products, Bedford, MA) or (2) $25 \mathrm{~mm}$ molded Aclar dishes coated with two layers of collagen I (Collaborative Biomedical Products) as described by Higgins et al. (1991). Because the latter substrate facilitates the neuronal-glial interactions that result in dendritic growth (D. Higgins, unpublished observations), functional studies examining the effect of reagents that antagonize BMP function on glial-induced dendritic growth were performed with cultures grown on collagen I. All other experiments were performed with cells grown on both types of substrates with each yielding qualitatively similar results. However, micrographs show only cultures grown on the poly-D-lysine/collagen IV substrate because this provided superior optical conditions. All cells were maintained in serum-free medium (Higgins et al., 1991) containing $\beta$-NGF $(100 \mathrm{ng} / \mathrm{ml}$; Harlan Bioproducts, Madison, WI). To eliminate endogenous non-neuronal cells from cultures, cytosine- $\beta$-D-arabinof uranoside ( $1 \mu \mathrm{M}$; Sigma) was added to the culture medium for $48 \mathrm{hr}$ beginning on day 2. Purified populations of glial cells were prepared from sympathetic ganglia as described in Tropea et al. (1988) and maintained in serum-free medium (Higgins et al., 1991) supplemented with heregulin- $\beta 1$ (100 $\mathrm{ng} / \mathrm{ml} ; \mathrm{R} \&$ D Systems).
Morphological analyses. Neuronal morphology was assessed in cultures immunostained with mAbs shown previously to react selectively with dendrites of sympathetic neurons (Lein et al., 1995). These included mAbs AP20 (Sigma) and SMI-52 (Sternberger Immunocytochemicals, Baltimore, MD), which are specific for MAP2, and mAb SMI-32 (Sternberger Immunocytochemicals) to nonphosphorylated forms of the $\mathrm{M}$ and $\mathrm{H}$ neurofilament subunits. All antigens were localized by indirect immunofluorescence using previously described procedures (Lein et al., 1995). Data in the text are presented as the mean \pm SEM, and statistical significance was determined using ANOVA followed by Fisher's LSD multiple comparison test.

Cell viability assay. Cell viability was determined using the Live/Dead Viability/Cytotoxicity Kit (Vaughan et al., 1995) from Molecular Probes (Eugene, OR). Viable cells were distinguished from nonviable cells on the basis of fluorescence: live cells cleave membrane-permeable calcein AM to yield cytoplasmic green fluorescence; in contrast, nonviable cells take up the membrane-impermeable ethidium homodimer-1, which labels nucleic acids with red fluorescence. Using MetaMorph Imaging software (Universal Imaging, West Chester, PA), the number of viable and nonviable cells was determined in 10 random fields $(5$ fields per culture) at $200 \times$ magnification.

Immunocytochemistry. Anti-BMP mAbs were used to localize BMP proteins in cells cultured from SCG as well as frozen tissue sections of SCG harvested from perinatal (E20, PN1, PN7) and adult rats. To detect total (intracellular and extracellular) BMP immunoreactivity, cultures were fixed in $4 \%$ paraformaldehyde and then permeabilized with methanol at $-20^{\circ} \mathrm{C}$ (Sigma) before addition of anti-BMP Ab $(10 \mu \mathrm{g} / \mathrm{ml})$. To detect BMPs associated only with the cell surface and extracellular spaces, cultures were incubated for $1 \mathrm{hr}$ at $4^{\circ} \mathrm{C}$ in serum-free $\mathrm{L} 15$ medium containing anti-BMP Ab $(10 \mu \mathrm{g} / \mathrm{ml})$ and $3 \%$ BSA before fixation in $4 \%$ paraformaldehyde. Immunoreactivity was visualized by indirect immunofluorescence as described previously (Lein et al., 1995). The specificity of the anti-BMP antibodies used in these studies was confirmed by preincubating each primary $\mathrm{mAb}$ with its specific blocking peptide or with peptides immunogenic for a different BMP family member before reaction with cultures. For all anti-BMP antibodies reported herein, preincubation with the specific blocking peptide but not with nonspecific BMP peptides reduced immunoreactivity to background levels.

To localize BMPs in intact tissues, sympathetic ganglia were fixed in $4 \%$ paraformaldehyde for $24 \mathrm{hr}$ at $4{ }^{\circ} \mathrm{C}$ and then equilibrated in $20 \%$ sucrose solution. Cryostat sections $(10 \mu \mathrm{m})$ were rinsed in PBS and then incubated in blocking solution (PBS, $\mathrm{pH} 7.4,5 \%$ BSA, $0.3 \%$ Triton $\mathrm{X}-100)$ for $1 \mathrm{hr}$ before reaction with anti-BMP Ab $(10 \mu \mathrm{g} / \mathrm{ml})$ for $1 \mathrm{hr}$. Primary antibody was localized using the Vectastain ABC-Peroxidase kit according to the manufacturer's instructions (Vector Laboratories, Burlingame, CA).

In situ hybridization. The probe constructs used to detect BMP transcripts were generated using highly divergent sequences primarily in the pro-region. Specific constructs included pO455-8, a 270 bp fragment of murine BMP6, and pO319-3, a fragment that encompasses amino acids $63-263$ of the pro region and the first 25 amino acids of the N-terminal domain of the mature polypeptide of murine BMP7 (Ozkaynak et al., 1992). To detect BMP mRNA in cultured cells, digoxigenin-labeled antisense and sense riboprobes were generated by in vitro transcription according to the manufacturer's instructions (Promega, Madison, WI). Cultures were fixed for $10 \mathrm{~min}$ in $4 \%$ paraformaldehyde after $4-5 \mathrm{~d}$ in culture, and in situ hybridization was performed under high stringency conditions as described previously (Zhai et al., 1997). Signal was detected with anti-digoxigenin Fab fragments conjugated to alkaline phosphatase (Boehringer Mannheim, Indianapolis, IN) using nitroblue tetrazolium (Boehringer Mannheim) as substrate.

To detect mRNA in tissue sections, SCG harvested from perinatal (E20, PN1, PN7) and adult rats were fixed in $4 \%$ paraformaldehyde for $24 \mathrm{hr}$ at $4^{\circ} \mathrm{C}$ and then equilibrated in $20 \%$ sucrose solution. Cryostat sections $(10 \mu \mathrm{m})$ were mounted on Fisherbrand Superfrost/Plus microscope slides (Fisher Scientific, Pittsburgh, PA). In situ hybridization with ${ }^{35}$ S-labeled cRNA probes was performed as described previously (Tiedge, 1991). Prehybridization, hybridization, and high-stringency washes were performed at $50^{\circ} \mathrm{C}$. For microscopic analyses, sections were dipped in NTB2 nuclear track emulsion (Eastman Kodak, Rochester, NY) diluted 1:1 with HPLC water. Sections were exposed for 3 weeks at $4^{\circ} \mathrm{C}$ and then counterstained with cresyl violet. Silver grain density was quantified in three different sections of each experimental condition using MetaMorph Imaging software (Universal Imaging). 
Table 1. Specific PCR primer sequences with expected size of PCR products used in RT-PCR analyses of mRNA from SCG and cultured SCG cells

\begin{tabular}{llll} 
mRNA target & Sense primer sequence $\left(5^{\prime}\right.$ to $3^{\prime}$ direction) & Antisense primer sequence $\left(5^{\prime}\right.$ to $3^{\prime}$ direction) & $\begin{array}{c}\text { Expected number of } \\
\text { base pairs }\end{array}$ \\
\hline BMP2 & CCAGGTTAGTGACTCAGAACAC & TCATCTTGGTGCAAAGACCTGC & 200 \\
BMP4 & TCTGGTCTCCGTCCCTATG & CTGAATCTCGGCGACTTTT & 414 \\
BMP5 & TTATGCAAAAGGAGGCTTGG & TCATGACCATGTCAGCATCA & 420 \\
BMP6 & CAGGACCTGGGATGGCAGGA & CATGCTCCCGCTGCACTGT & 200 \\
BMP7 & ATTTCAGCCTGGACAACGAG & TGGAAAGATCAAACCGGAAC & 412 \\
Noggin & GAGCAAGAAGCTGAGGAGGA & GTGAGGTGCACAGACTTGGA & 192 \\
Follistatin & CGGAACCCTCATCTTCAGAG & GCCAACCTTGAAATCCATA & 200 \\
18S rRNA & GTAACCCGTTGAACCCCATT & CCATCCAATCGGTAGTAGCG &
\end{tabular}

Immunoprecipitation and Western blot analyses. Conditioned medium was collected and concentrated $\sim 5 \times$ in the presence of $100 \mu \mathrm{g} / \mathrm{ml}$ PMSF and $300 \mu \mathrm{g} / \mathrm{ml}$ aprotinin (Sigma) by centrifugal filtration at $6000 \times g$ using membranes with a molecular weight cutoff of $10 \mathrm{kDa}$. Adherent cells were rinsed with ice-cold PBS and then triturated in ice-cold lysis buffer (1\% Igepal, $0.5 \%$ sodium deoxycholate, $0.1 \%$ SDS, $100 \mu \mathrm{g} / \mathrm{ml} \mathrm{PMSF}$, and $300 \mu \mathrm{g} / \mathrm{ml}$ aprotinin). Cell lysates were microf uged at maximal speed for $5 \mathrm{~min}$, and the protein concentration of the resultant supernatant was determined using the Bradford assay (Bio-Rad, Hercules, CA). For immunoprecipitation, supernatants volume-adjusted to contain equal amounts of protein were incubated with BMP-specific antibodies (each at $10 \mu \mathrm{g} / \mathrm{ml}$ ) and Protein A/Protein-G Sepharose beads (Pierce, Rockford, IL) at $10 \mu \mathrm{l} / \mathrm{ml}$ for $1 \mathrm{hr}$ at $4^{\circ} \mathrm{C}$. The beads were then washed successively in buffer C (50 mM Tris, $\mathrm{pH} 8.0$, $500 \mathrm{~mm} \mathrm{NaCl}, 0.1 \% \mathrm{NP}-40,1 \mathrm{~mm}$ EDTA, $0.25 \%$ gelatin, $0.02 \%$ NaAzide), lysis buffer, and buffer E (10 mM Tris, pH 7.5, 0.1\% NP-40) followed by extraction with $8 \mathrm{M}$ guanidine $\mathrm{HCl}$ in Tris buffer $(10 \mathrm{~mm}$, $\mathrm{pH}$ 7.4). Immunoprecipitates or cell lysate and conditioned medium samples containing equivalent amounts of protein were resolved by $12 \%$ SDS-PAGE under reducing conditions and then electroblotted onto polyvinylidene difluoride membranes. Blots were blocked at room temperature for $1 \mathrm{hr}$ in TBS-T $(10 \mathrm{~mm}$ Tris, $\mathrm{pH} 8.0,150 \mathrm{~mm} \mathrm{NaCl}$, $0.1 \%$ Tween 20 ) containing $5 \%$ dried fat-free milk and then incubated overnight at $4{ }^{\circ} \mathrm{C}$ in TBS-T containing $0.5 \%$ milk and primary $\mathrm{Ab}(0.5$ $\mu \mathrm{g} / \mathrm{ml}$ for antibodies against BMP2, $-4,-5$, and -6 and follistatin mAb; $1 \mu \mathrm{g} / \mathrm{ml}$ for anti-BMP7 polyclonal $\mathrm{Ab} ; 20 \mathrm{ng} / \mathrm{ml}$ for noggin $\mathrm{mAb}$ RP57-16). Blots were washed twice with TBS-T containing $0.5 \%$ milk and then incubated at room temperature for $2 \mathrm{hr}$ in TBS-T containing $0.5 \%$ milk and HRP-conjugated secondary Ab. Subsequently, blots were washed three times as described above and visualized using an enhanced chemiluminescence detection method (ECL, Amersham Biosciences, Arlington Heights, IL). Blots of cell lysates were stripped and reprobed using antibodies specific for $\alpha$-tubulin (1:10,000; Sigma). To quantify data, films were scanned using an HP ScanJet ADF scanner and HP Precision ScanPro software, and band density was determined as arbitrary absorption units using the MacBas software program (version 2.31, Fuji Film).

$R N A$ isolation and analyses. Total RNA was extracted from freshly harvested SCG using Trizol (Invitrogen, Carlsbad, CA) and from cultured cells using RNeasy (Qiagen, Valencia, CA) as specified by the manufacturer. RNA samples $(3 \mu \mathrm{g})$ were reverse transcribed using random primers at annealing temperatures of $65^{\circ} \mathrm{C}$ (You-Prime-theFirst-Strand kit, Amersham Biosciences, Piscataway, NJ). Resultant cDNA was amplified by PCR using primers described in Table 1. Preliminary experiments in which product formation was determined as a function of cycle number were used to select the cycle number for each primer set that corresponded to the upper end of the linear response range. Amplification programs were set using annealing temperatures ranging from 55 to $62^{\circ} \mathrm{C}$, depending on the primer set, for $1 \mathrm{~min}$ and denaturing temperature of $94^{\circ} \mathrm{C}$ for $1 \mathrm{~min}$; the $\mathrm{Mg}^{2+}$ concentration was 1.5 mM. As a negative control, each sample was run through PCR without previous reverse-transcription. After synthesis, PCR products were subjected to $1 \%$ agarose gel electrophoresis and found to have the expected sizes (Table 1).

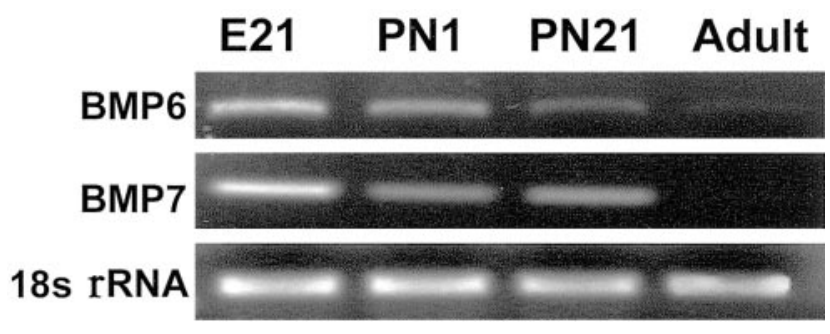

Figure 1. BMP mRNA is expressed in SCG at times corresponding to initial and maximal dendritic growth. Transcripts for BMP6 and BMP7 are detected by RT-PCR in total RNA extracted from rat SCG at E21. PCR products for both BMPs are still present at PN1 but decline over development such that expression is not evident in equal amounts of total RNA isolated from adult SCG. In contrast, levels of $18 \mathrm{~S}$ rRNA are not altered as a function of developmental stage.

\section{RESULTS}

\section{BMP translational and transcriptional products are expressed in sympathetic ganglia during periods of maximal dendritic growth}

Preliminary RT-PCR analyses of total RNA isolated from perinatal rat SCG detected transcripts for BMP5, -6, and -7, low levels of BMP2 mRNA, but no BMP4 mRNA; thus subsequent studies focused on the 60A BMP subfamily members. Using $18 \mathrm{~S}$ rRNA as an internal standard, comparative RTPCR analyses of BMP mRNA in SCG of animals of varying ages indicated that mRNA for BMP6 and -7 is present in SCG during periods of initial and maximal growth of dendrites in sympathetic neurons (E21 to PN1). However, transcript levels are significantly downregulated during later stages of dendritic maturation (PN21) and are not detectable in SCG of adult animals (Fig. 1). Previously we reported a similar temporal pattern of mRNA expression for BMP5 (Beck et al., 2001). Immunocytochemical analyses indicate that protein levels of BMP5, -6 , and -7 follow a similar pattern of developmental expression. As illustrated in a sample immunostained with BMP7 mAb (Fig. 2A), significant BMP immunoreactivity is present in SCG of PN1 rat pups. Labeling is evident throughout the cellular and extracellular spaces of the SCG but is clearly excluded from neuronal nuclei. BMP7 immunoreactivity is also observed throughout the SCG of E20 and PN7 pups but is significantly downregulated in the adult SCG. Similar spatiotemporal expression patterns are observed in sections of SCG immunostained with antibodies selective for BMP5 or -6 (data not shown). In situ hybridization analyses indicate that SCG also express mRNA for BMP6 and -7 (Fig. 2D,E,G). 

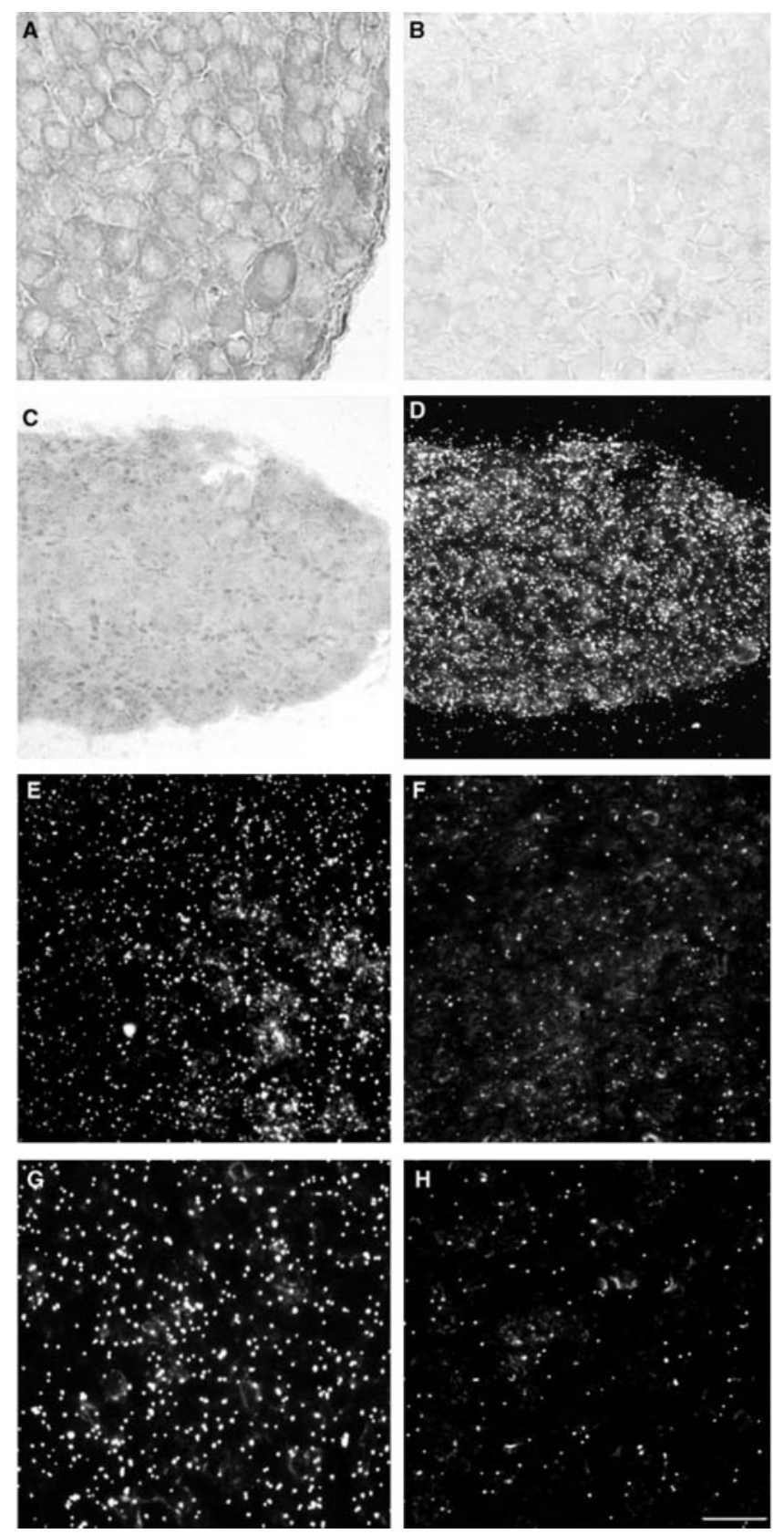

Figure 2. BMP protein and transcript are present in sympathetic ganglia of perinatal rat pups during the time of rapid growth and expansion of the dendritic arbor. $A, B$, Bright-field micrographs of HRP reaction product in frozen sections from SCG of a PN1 rat pup. $A$, Sections immunostained with $\mathrm{mAb} 12 \mathrm{G} 3$ raised against BMP7 exhibit significant HRP reaction product throughout the neuronal cytoplasm and in extracellular spaces; in contrast, labeling is not observed in neuronal nuclei. $B$, Labeling is not observed in control sections treated only with the secondary antibody. $C, D$, Bright-field $(C)$ and dark-field $(D)$ micrographs $(200 \times)$ of a SCG from a PN7 rat pup hybridized with ${ }^{35} \mathrm{~S}$-labeled riboprobes and counterstained with cresyl violet. Sections hybridized with BMP7 antisense probe $(C, D)$ show significant labeling throughout most of the ganglion. Higher magnification $(400 \times)$ dark-field images of SCG from a PN7 rat hybridized with ${ }^{35}$ S-labeled BMP7 antisense $(E)$ or BMP6 antisense $(G)$ probes exhibit diffuse distribution of grains. The grain density in sections labeled with BMP7 or BMP6 antisense probes $\left(3.2 \times 10^{6} \pm 0.14 \times 10^{6}\right.$ grains $/ \mathrm{cm}^{2}$ and $3.3 \times 10^{6} \pm 0.05 \times 10^{6}$ grains $/ \mathrm{cm}^{2}$, respectively) is significantly greater than the grain density observed in sections hybridized with BMP7 sense probe $(F)\left(0.6 \times 10^{6} \pm 0.06 \times 10^{6}\right.$ grains $\left./ \mathrm{cm}^{2}\right)$ or BMP6 sense probe $(H)$ $\left(0.73 \times 10^{6} \pm 0.06 \times 10^{6}\right.$ grains $\left./ \mathrm{cm}^{2}\right)$. Scale bar: $200 \times$ magnification, 50 $\mu \mathrm{m} ; 400 \times$ magnification, $25 \mu \mathrm{m}$.
Consistent with BMP protein expression, BMP mRNA label is distributed throughout the ganglia, and the densest labeling is observed in SCG from E20 embryos, less dense labeling is observed in PN7 SCG, and negligible labeling is observed in the adult SCG. These data indicate that transcriptional and translational products for BMP5, -6 , and -7 are present in the SCG at times corresponding to initial growth and rapid expansion of the dendritic arbor.

\section{BMPs are synthesized by SCG glia and neurons in vitro}

The BMP localization studies in intact ganglia clearly indicate that the spatiotemporal pattern of BMP expression is consistent with a proposed role for BMPs in regulating dendritic growth in SCG neurons. To determine which cell type(s) might produce and bind BMPs in developing SCG, we assessed both surface and cytoplasmic immunoreactivity of BMP proteins in cultured SCG cells. Neuron-glia cocultures derived from embryonic SCG and grown for 1-2 weeks in vitro before immunostaining exhibit significant levels of endogenous BMP5, -6, and -7 . The distribution of secreted BMPs was determined by reacting cultures with BMP antibodies before fixation and permeabilization. As illustrated in a neuron-glia coculture immunostained for BMP7, neuronal somata exhibit diffuse surface immunoreactivity, and neuronal processes are clearly delineated by punctate staining (Fig. $3 A, B$ ). Surface staining of glial cells is difficult to detect; however, BMP7 immunoreactivity is clearly observed in most if not all ganglionic glial cells in cocultures permeabilized before reaction with BMP7 $\mathrm{mAb}$ (Fig. 3C,D). Glial BMP7 staining is evident throughout the cytoplasm but is excluded from the nucleus (Fig. 3C). Neuronal somata and processes also react strongly with BMP7 $\mathrm{mAb}$ in permeabilized cultures (Fig. 3C). Neuronal staining appears brighter than glial staining, attributable in part to the fact that the soma of neurons is thicker than that of cultured glial cells. Similar patterns of immunoreactivity were observed in neuron-glia cocultures immunostained with Ab selective for BMP5 (Beck et al., 2001) and BMP6 (Fig. 3E). To determine whether neuronal immunoreactivity for BMPs reflects uptake of BMPs originating from glial cells or possible neuronal production of BMPs, BMP7 immunoreactivity was assessed in neurons cultured in the absence of glial cells. Although not as intense as in neuron-glia cocultures (Fig. $3 C$ ), significant staining with BMP7 $\mathrm{mAb}$ is observed in neurons permeabilized before reaction with BMP7 mAb (Fig. 3G). However, little to no surface immunoreactivity is observed in neurons reacted with BMP7 mAb before permeabilization (Fig. $3 H$ ).

These observations suggested that neurons were capable of producing BMPs; however, an alternative interpretation is that neuronal immunoreactivity reflects BMPs internalized by neurons before dissociation for culture. To determine whether both neuronal and glial cell types are capable of BMP synthesis, cocultures were analyzed by in situ hybridization using probes specific for BMP6 or -7. Transcripts for BMP7 (Fig. $4 A$ ) and BMP6 (Fig. $4 C$ ) are present throughout the cytoplasm of ganglionic glial cells. Neurons cocultured with glial cells also exhibit heavy somatic labeling for BMP7 (Fig. $4 A$ ) and BMP6 (Fig. 4C) mRNA. This latter observation was not expected because sympathetic neurons grown in the absence of glial cells typically do not extend dendrites (Tropea et al., 1988) (see Fig. 8). Therefore, we examined the expression of mRNA for BMP6 and -7 in neurons grown in the absence of ganglionic 

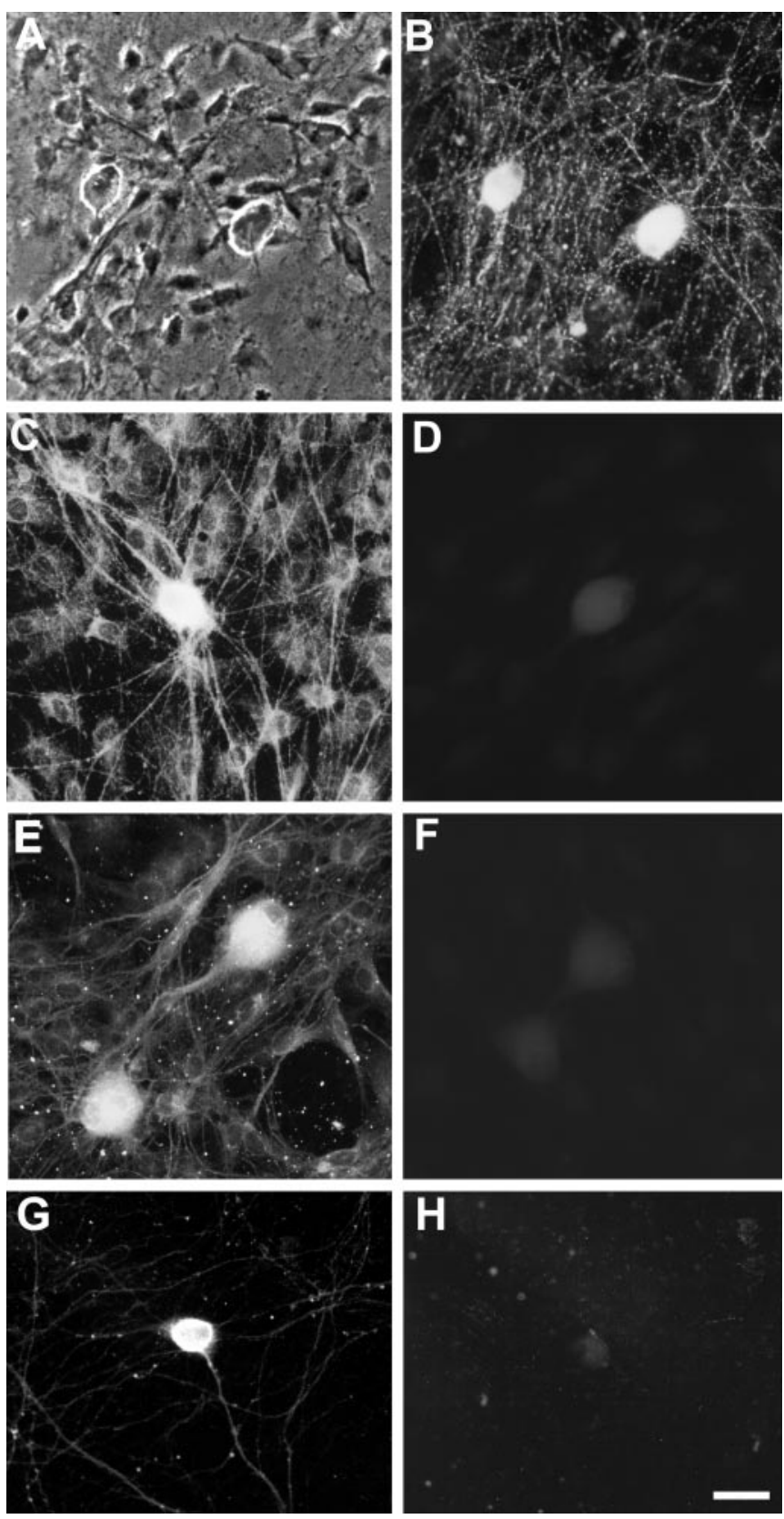

Figure 3. BMP immunoreactivity is associated with both ganglionic glial cells and sympathetic neurons in coculture. $A, B$, Phase-contrast $(A)$ and fluorescence $(B)$ micrographs of cocultures reacted with $\mathrm{mAb}$ $12 \mathrm{G} 3$ against BMP7 before fixation or permeabilization. Neuronal soma exhibit diffuse cell surface immunoreactivity, and neuronal processes are clearly delineated by a punctate staining pattern. $C$, In cocultures immunostained with mAb $12 \mathrm{G} 3$ after fixation and permeabilization, BMP7 immunoreactivity is evident throughout the cytoplasm of both glial cells and neurons. In neurons, the processes as well as the soma are brightly stained. $D$, Preincubation of mAb $12 \mathrm{G} 3$ with recombinant BMP7 significantly decreases BMP7 immunoreactivity in permeabilized cocultures. $E$, Both neurons and glial cells exhibit BMP6 immunoreactivity throughout their cytoplasm, which is significantly reduced by preincubating BMP6 antiserum with specific blocking peptide $(F)$. Immunocytochemical localization of BMP7 in neurons cultured in the absence of glial cells $(G, H)$ indicates significant immunoreactivity in the soma and processes of neurons permeabilized before reaction with BMP7 mAb $(G)$, but very little if any surface staining for BMP7 in neurons reacted with BMP7 mAb before permeabilization $(H)$. Scale bar, $50 \mu \mathrm{m}$.
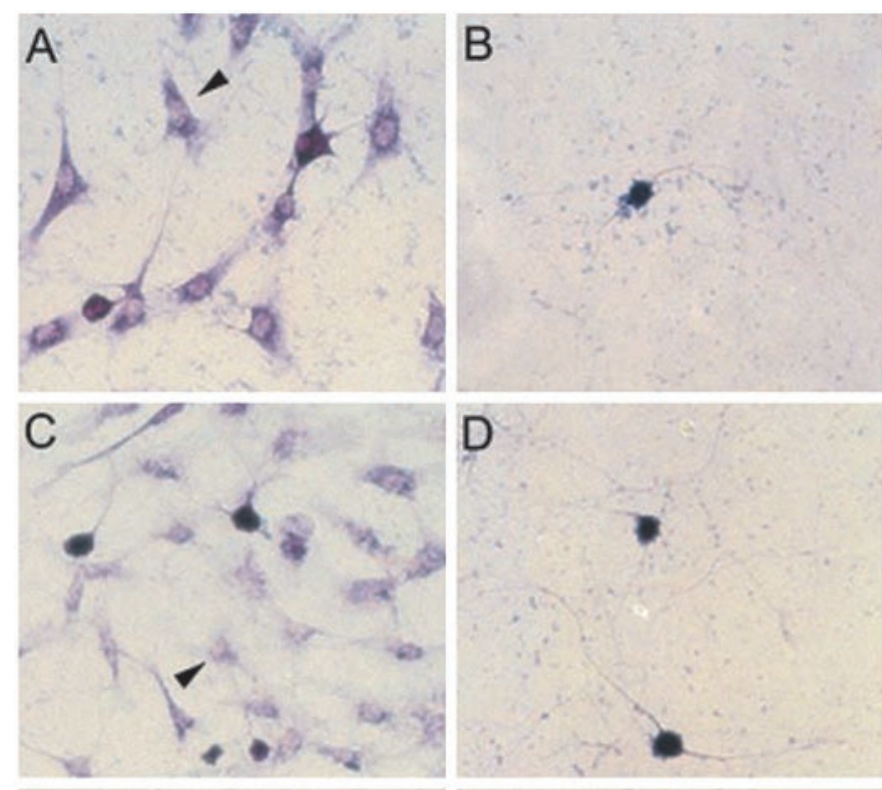

E

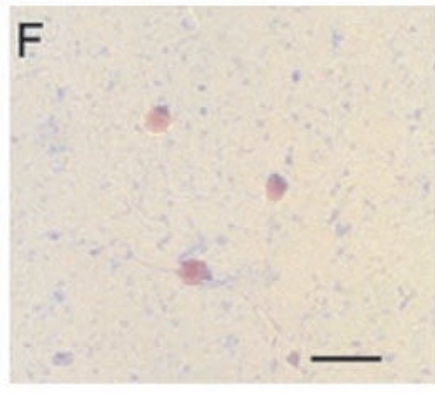

Figure 4. Cultured ganglionic glial cells and sympathetic neurons express BMP6 and -7 mRNA. Sympathetic neurons were grown for $4-5 \mathrm{~d}$ in the presence $(A, C, E)$ or absence $(B, D, F)$ of ganglionic glial cells before hybridization with digoxigenin-labeled antisense riboprobes for BMP7 $(A, B)$ or BMP6 $(C, D)$. Glial cells (arrowhead) express mRNA for BMP7 $(A)$ and BMP6 $(C)$ throughout their cytoplasm. Neurons cocultured with ganglionic glial cells also exhibit intense somatic labeling for BMP7 $(A)$ and BMP6 $(C)$ transcripts. A similar distribution of BMP7 $(B)$ and BMP6 $(D)$ mRNA is observed in neurons grown in the absence of glia. Negligible labeling is observed in either neurons or glial cells hybridized with BMP7 sense riboprobe $(E, F)$. Scale bar, $50 \mu \mathrm{m}$.

glial cells. Even under these culture conditions, neurons exhibit significant labeling for BMP7 (Fig. 4B) and BMP6 (Fig. 4D) mRNA.

\section{BMP expression is upregulated in neuron-glial cocultures}

The in situ hybridization data suggest that both neurons and glia transcribe BMP mRNA but do not indicate whether both cell types translate and secrete BMPs, nor do these data reveal whether coculturing neurons with glia alters patterns of BMP protein expression. To address these questions, we used Western blot analyses to compare levels of BMP2, $-4,-5,-6$, and -7 in cell lysates and conditioned medium of SCG neurons and glia grown in the absence or presence of each other. The specificity of the antibodies used in these studies is illustrated in Figure 5. All cultures expressed BMP5, -6 , and -7 but not BMP2 and -4 (Fig. 6). A representative blot probed with BMP7 mAb (Fig. $5 B$ ) illustrates that conditioned medium and cell lysates of neuronglia cocultures typically yield one or two bands with the higher 


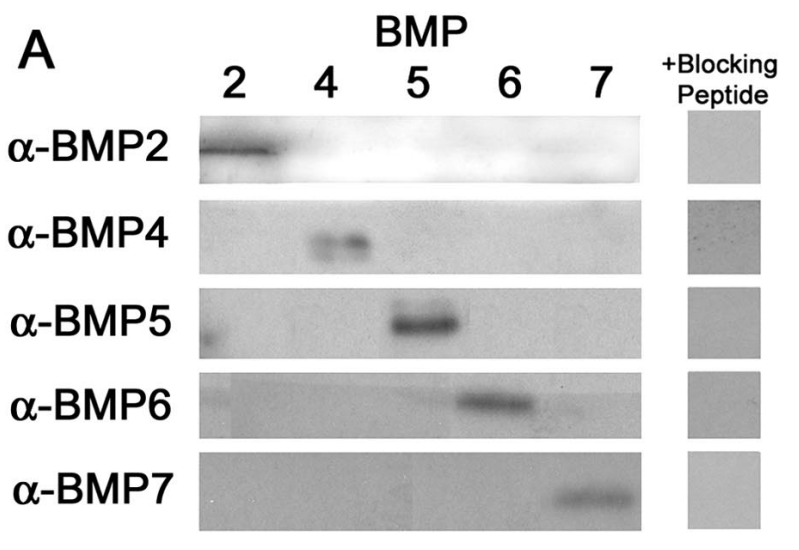

B

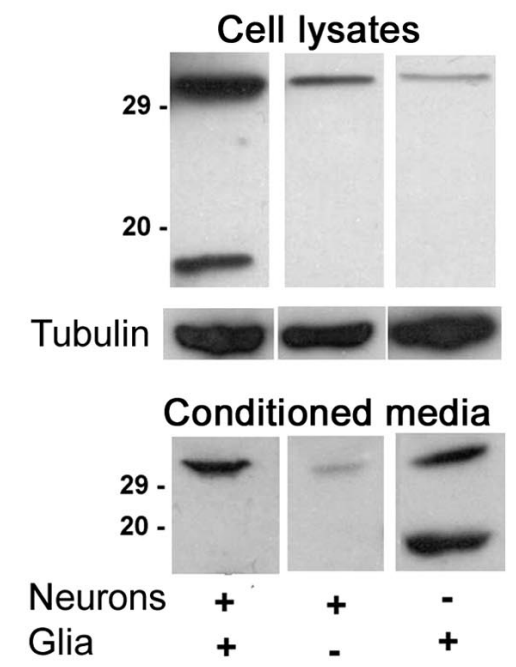

Figure 5. Western blot analyses of BMPs in cocultures of sympathetic neurons and ganglionic glial cells. $A$, The specificity of the antibodies used for Western blot analysis was evaluated by reacting blots of recombinant BMP2, $-4,-5,-6$, or $-7(50 \mathrm{ng})$ with antibodies raised against each of these BMPs. Each BMP antibody $(0.5 \mu \mathrm{g} / \mathrm{ml})$ reacted only with the BMP against which it was raised, and this interaction was inhibited by preincubation of the antibody with specific blocking peptide $(2.5 \mu \mathrm{g} / \mathrm{ml}) . B$, Cell lysates and conditioned medium from neuron and glial cocultures (far left lane), purified neuronal cultures (middle lane), or purified cultures of ganglionic glial cells ( far right lane) were probed using antibody selective for BMP7. Equal amounts of protein were loaded into all wells, and blots of cell lysates were also probed for $\alpha$-tubulin. The levels of both the monomeric $(\sim 17$ $\mathrm{kDa})$ and dimeric $(\sim 30 \mathrm{kDa})$ forms of BMP7 varied between the different culture conditions.

and lower molecular weight bands corresponding to the dimeric and monomeric forms of the mature BMP7 protein, respectively. Significantly less BMP7 is present in purified neuronal cultures, and it is mostly in the dimeric form (Fig. 5B). In this sample, BMP7 appears to be mostly absent from the conditioned medium; however, this pattern was not observed consistently in all samples from purified neuronal cultures (Fig. 6). Purified glial cultures express both the dimeric and monomeric forms of BMP7, which in all samples were found predominantly in the conditioned medium. Densitometric analyses of Western blots of cell lysates and conditioned medium from neurons grown in the absence or presence of ganglionic glial cells indicate significantly increased levels of BMP5, -6 and, -7 in neuron-glia cocultures relative to cultures of neurons only (Fig. $6 A, B$ ). In contrast, levels of $\alpha$-tubulin in cell lysates did not change as a function of culture condition
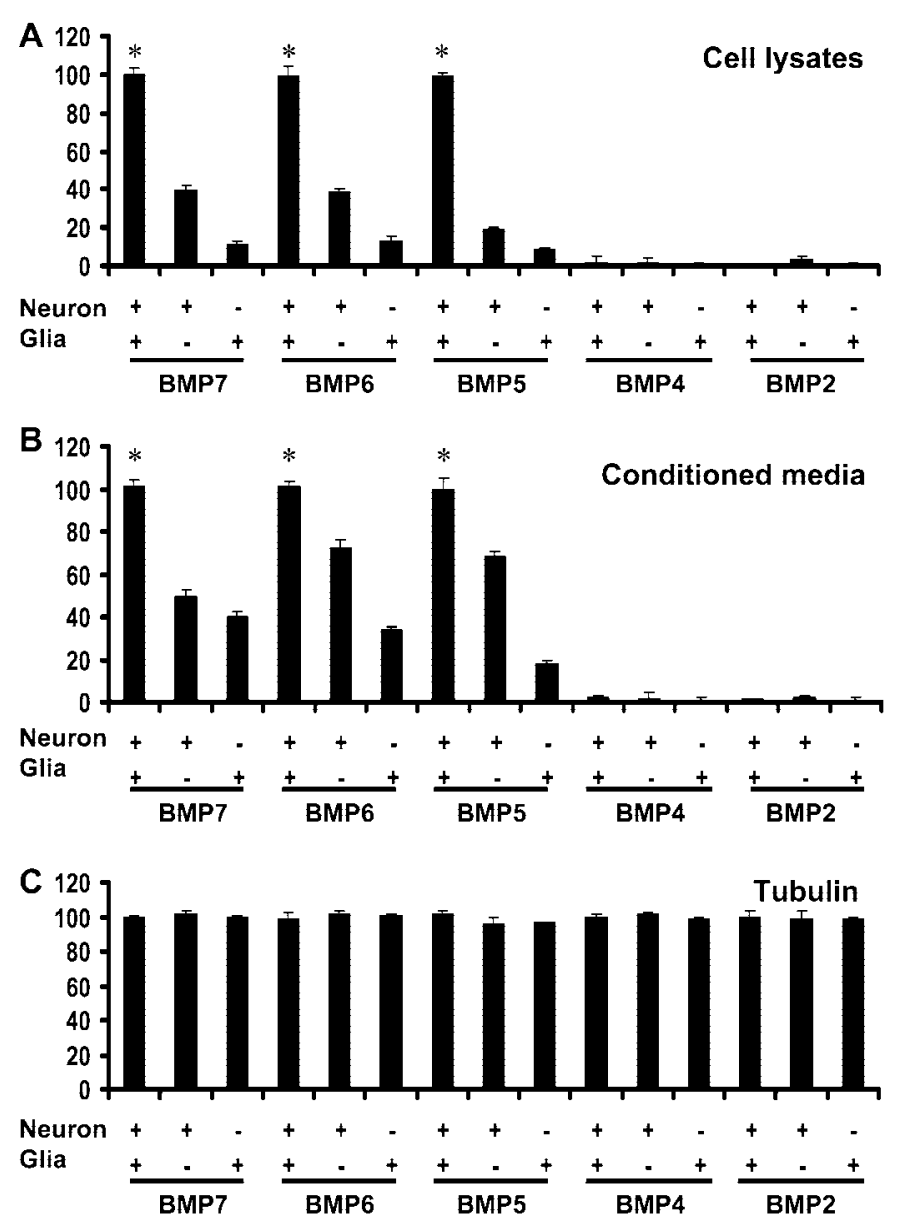

Figure 6. BMPs are present in significantly greater concentrations in cocultures of sympathetic neurons and ganglionic glial cells relative to cultures of neurons only or glial cells only. $A, B$, Densitometric analyses of Western blots of cell lysates $(A)$ and conditioned medium $(B)$ from cocultures of sympathetic neurons and ganglionic glia, cultures of neurons only, or cultures of ganglionic glial cells only. Equal amounts of proteins were loaded into all wells, probed with antibodies selective for BMP7, -6, $-5,-4$, or $-2(0.5 \mu \mathrm{g} / \mathrm{ml})$, and quantified by densitometry. Bars represent levels of total (combined dimeric and monomeric) BMP. $C$, Blots of cell lysates were also probed for $\alpha$-tubulin. Data are presented as the mean \pm SEM ( $n=3$ per condition). ${ }^{*} p<0.01$ versus corresponding value for neuron-glia cocultures.

(Fig. 6C). These data suggest that neurons are capable of producing BMPs, but the level of production in neurons cultured in the absence of glia is significantly less than that observed in neuron-glia cocultures.

\section{Coculture with glia decreases levels of surface BMP complexed with BMP antagonists}

In addition to altering BMP expression, BMP signaling can be regulated by modulating expression of soluble BMP antagonists that bind BMPs to prevent functional interactions between BMPs and their cognate receptors. Preliminary RT-PCR analyses using primers specific for noggin, follistatin, Cerberus, or gremlin indicated that noggin and follistatin transcripts are the predominant BMP antagonists detected in perinatal rat SCG. Noggin and follistatin mRNA are abundantly expressed in intact SCG at E20 and then decrease from PN3 to PN7 (Fig. 7A). RT-PCR analyses of purified cultures of neurons or glia indicate that both 


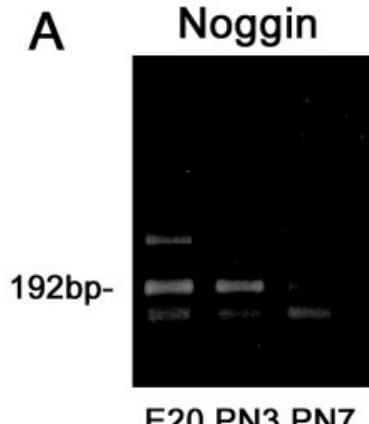

E20 PN3 PN7
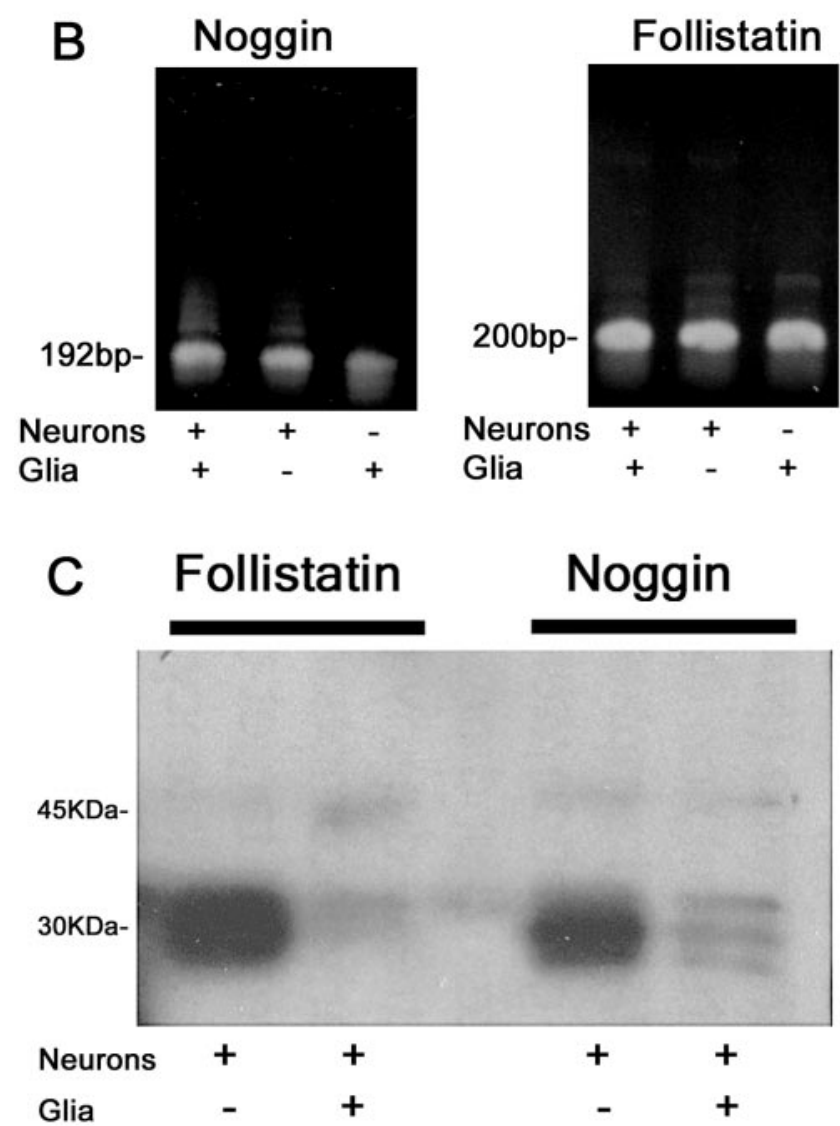

Figure 7. Expression of the BMP antagonists noggin and follistatin in SCG cells. $A$, Noggin and follistatin mRNA were detected by RT-PCR in total RNA extracted from rat SCG at E20 and PN3, which correspond to times of initial dendrite extension (E20) and rapid expansion of the dendritic arbor $(P N 3)$ in these neurons. At later developmental times when the dendritic arbor is undergoing maximal expansion (PN7), transcript levels for both noggin and follistatin decrease. $B$, RT-PCR analyses of total RNA from cultured SCG cells indicate that both neurons and glial cells express noggin and follistatin mRNA, and these levels are not altered significantly by coculture. $C$, Protein immunoprecipitated with BMP antibodies from neuron-glia cocultures or neuron monocultures probed with antibodies specific for noggin or follistatin. Coculture of neurons with glial cells significantly decreases levels of BMPs complexed to noggin and follistatin relative to levels present in neuronal monocultures.

cell types express noggin and follistatin mRNA and that coculture does not appear to significantly alter levels of mRNA for either antagonist (Fig. 7B). To determine the effects of coculture on levels of BMP complexed to antagonist, blots of proteins
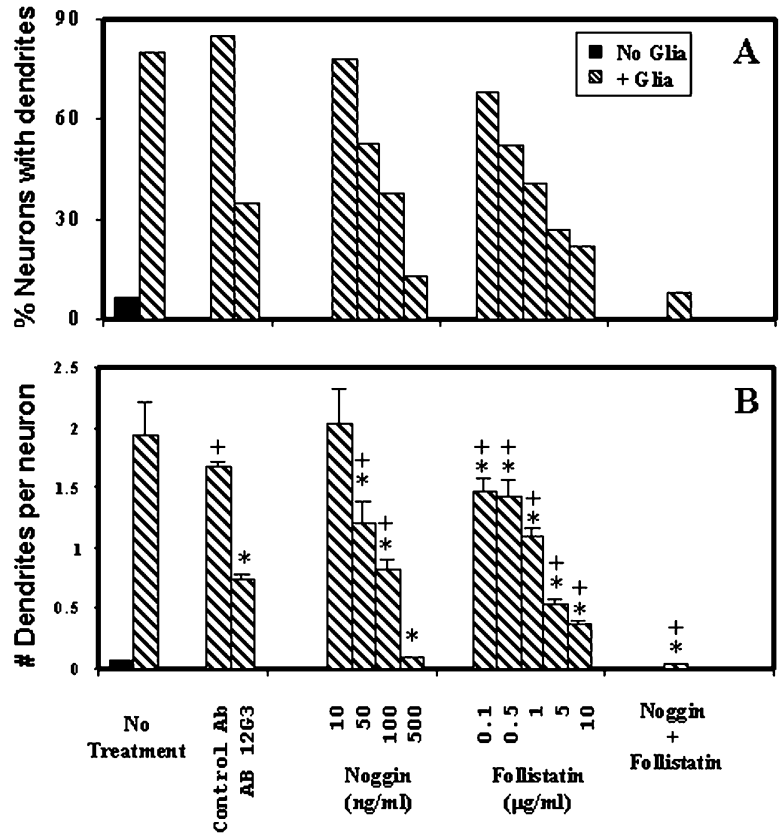

Figure 8. Reagents that block BMP function inhibit glial-induced dendritic growth. Sympathetic neurons were cocultured with ganglionic glial cells in the absence or presence of mAb $12 \mathrm{G} 3$ raised against BMP7 $(15 \mu \mathrm{g} / \mathrm{ml})$ or an isotype-matched control antibody $(15 \mu \mathrm{g} / \mathrm{ml})$, or varying concentrations of the BMP antagonists noggin and follistatin. After 12-14 d of exposure to these reagents, cultures were immunostained for MAP-2, and dendritic growth was quantified as the percentage of neurons with dendrites $(A)$ and the number of dendrites per neuron $(B)$. Data are represented as the mean $\pm \operatorname{SEM}(n \geq 70$ per condition). ${ }^{*} p<0.001$ versus neuron-glia cocultures grown in the absence of BMP function-blocking reagents; ${ }^{+} p<0.001$ versus neurons cultured in the absence of glia.

immunoprecipitated from neurons cultured in the absence or presence of glia using a mixture of antibodies that recognize BMP5, -6 , and -7 were probed with antibodies to either follistatin or noggin. Consistent with earlier observations, BMP levels were increased by coculture (data not shown); however, levels of BMPs complexed to noggin and follistatin were significantly decreased by coculture (Fig. 7C).

\section{Glial-induced dendritic growth is blocked by antagonists of BMP function}

Sympathetic neurons dissociated from the SCG of embryonic rats were maintained in serum-free medium, and ganglionic nonneuronal cells were eliminated from all cultures during the first few days in vitro by exposure to an antimitotic agent. After 5-7 d in vitro, neuronal cultures were reseeded with highly purified populations of glial cells originally derived from sympathetic ganglia. Consistent with previous studies (Tropea et al., 1988), within 2 weeks after adding glial cells to cultures, $75-85 \%$ of the neuronal cell population had extended one to three distinct dendrites; in contrast, neurons maintained in the absence of glia had very little dendritic growth (Fig. 8).

To test the hypothesis that BMPs mediate glial-induced dendritic growth, BMP activity was inhibited using either functionblocking BMP7 mAb or soluble antagonists of BMP action. These reagents were initially added to the culture medium $3 \mathrm{~d}$ after reseeding with ganglionic glial cells, and the medium was continuously replenished with the appropriate reagent at each subsequent medium exchange. All cultures were analyzed for 
dendritic growth at the end of the third week in vitro. In the presence of the function-blocking anti-BMP7 mAb (Vukicevic et al., 1994), the percentage of neurons with dendrites and the number of dendrites per neuron were reduced by 56 and $62 \%$, respectively (Fig. $8 A, B$ ). Similar results were obtained using BMP7 $\mathrm{mAb}$ that recognizes a different epitope of BMP7 (data not shown). Concentrations of anti-BMP7 $\mathrm{mAb}>15 \mu \mathrm{g} / \mathrm{ml}$ did not cause further inhibition of dendritic growth. Isotype-matched control antibody at similar concentrations had no inhibitory effect on either parameter of dendritic growth.

The observation that mAbs selective for BMP7 did not completely block glial-induced dendritic growth is not surprising because BMP5 and -6 are also present in these cocultures, and both have been reported to promote dendritic growth in sympathetic neurons (Guo et al., 1998; Beck et al., 2001). Because function-blocking antibodies selective for these additional BMPs are not available, we tested the hypothesis that multiple BMPs mediate glial-induced dendritic growth by exposing neuron-glia cocultures to exogenous noggin or follistatin. Preliminary studies indicated that the dendrite-promoting activity of recombinant BMP2, $-4,-5,-6$, and -7 at concentrations that induce robust dendritic growth in cultured sympathetic neurons $(10-20 \mathrm{ng} / \mathrm{ml})$ (Lein et al., 1995; Guo et al., 1998) was significantly inhibited by both BMP antagonists in a concentration-dependent manner [see also Beck et al. (2001)]. Noggin (500 ng/ml) blocked the dendritepromoting activity of BMP2 and -4 almost completely (97\% inhibition) and significantly reduced the effect of BMP5, -6 , and -7 ( $\sim 80 \%$ inhibition $)$. Follistatin $(10 \mu \mathrm{g} / \mathrm{ml})$ strongly antagonized the effects of BMP5, -6 , and -7 on dendritic growth $(85-95 \%$ inhibition) and significantly decreased that of BMP2 and -4 (60$75 \%$ inhibition).

The addition of noggin or follistatin to neuron-glia cocultures significantly reduced both the percentage of neurons with dendrites (Fig. $8 A$ ) and the number of dendrites per neuron (Fig. $8 B)$. This inhibition of glial-induced dendritic growth was concentration dependent, with maximal effects observed at $500 \mathrm{ng} / \mathrm{ml}$ for noggin and $10 \mu \mathrm{g} / \mathrm{ml}$ for follistatin. These concentrations are comparable with those previously reported to block BMP effects on other developmental endpoints in cultured neurons (Ai et al., 1999; Li and LoTurco, 2000; Lim et al., 2000). A combined exposure to maximally effective concentrations of noggin and follistatin reduced dendritic growth to levels observed in sympathetic neurons cultured in the absence of glia.

Morphometric analyses of cultures by phase-contrast microscopy indicated that treatment with noggin or follistatin had no effect on the density or viability of neurons or glia. Thus, in all cultures examined, the axonal plexus appeared intact, glial cells were confluent across the dish, and neuronal somata were surrounded by glia. To confirm these observations, neuronal cell number and total cell viability were assessed in neuron-glia cultures grown in the absence or presence of BMP antagonists. The number of neurons per $35 \mathrm{~mm}$ dish of neuron-glia cocultures ( $n=3$ per condition) exposed to $500 \mathrm{ng} / \mathrm{ml}$ noggin $(21,712 \pm$ 1987 neurons per $35 \mathrm{~mm}$ dish), $10 \mu \mathrm{g} / \mathrm{ml}$ follistatin $(17,498 \pm$ 1699), or noggin and follistatin at maximal concentrations $(18,317 \pm 2454)$ did not differ significantly from that of cocultures grown in the absence of BMP antagonists (20,049 \pm 3541). Similarly, BMP antagonists did not alter the number of viable cells (which includes neuronal and glial cells) as determined by incorporation of calcein and ethidium-homodimer-1 dyes. When expressed as a percentage of control (cocultures not exposed to BMP antagonists), the number of viable cells in

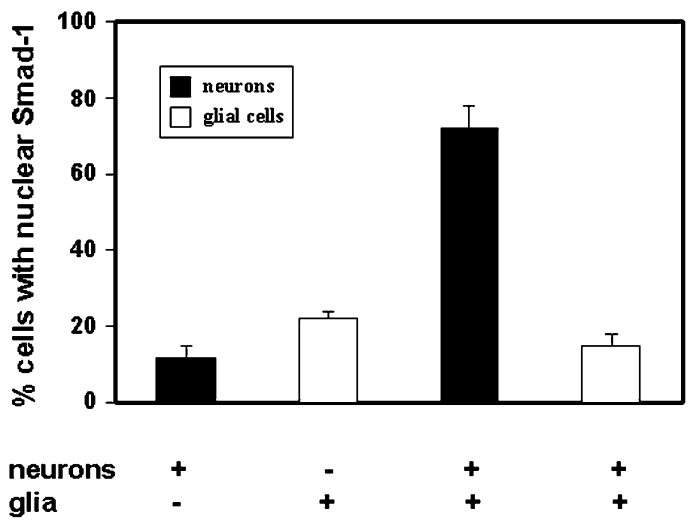

Figure 9. Coculture of sympathetic neurons with ganglionic glial cells induces Smad-1 nuclear translocation in neurons but not in glial cells. After $5 \mathrm{~d}$ in vitro, a subset of neuronal cultures was reseeded with highly purified populations of ganglionic glial cells. Some of the glial cell suspension was plated into dishes without neurons. Three days after plating the glial cells, neuronal monocultures, glial monocultures, and neuronglia cocultures were immunostained for Smad-1, and the percentage of neurons and glial cells with nuclear Smad-1 localization was quantified. In neurons and glial cells grown in monoculture, Smad-1 was predominantly localized to the cytoplasm. Coculture of neurons with glia did not alter the distribution of Smad-1 in glial cells but did significantly increase the percentage of neurons with nuclear Smad-1 localization. Data are represented as the mean \pm SEM $(n=20$ microscopic fields at $200 \times$ magnification; 5 fields each from 4 different cultures from 2 separate dissections).

cocultures exposed to $500 \mathrm{ng} / \mathrm{ml}$ noggin was $96 \pm 2 \% ; 10 \mu \mathrm{g} / \mathrm{ml}$ follistatin, $105 \pm 6 \%$; noggin and follistatin, $98 \pm 4 \%$. These data suggest that the inhibition of dendritic growth by these BMP antagonists does not result from compromised neuronal or glial cell viability.

\section{Addition of glia to neuronal cultures increases nuclear translocation of Smad-1 in neurons but not glia}

Increased BMP activity in neuron-glia cocultures could directly induce dendritic growth in neurons via interaction with neuronal $\mathrm{BMP}$ receptors or indirectly via interaction with glial BMP receptors. BMP ligand binding to their receptors activates Smad transcription factors, which subsequently translocate from the cytoplasm to the nucleus. To determine which cell type BMPs activated in neuron-glia cocultures, the distribution of Smad-1 immunoreactivity was assessed in purified cultures of neurons or glia and in neuron-glia cocultures (Fig. 9). Consistent with previous observations (Guo et al., 2001), Smad-1 immunoreactivity was restricted primarily to the cytoplasm in purified cultures of neurons. However, as observed when sympathetic neurons are treated with recombinant BMPs (Guo et al., 2001), when cocultured with glia, most neurons also exhibited Smad-1 immunoreactivity in the nucleus. In glial cells grown in purified culture, Smad-1 was localized predominantly in the cytoplasm, and coculturing with neurons did not alter this pattern of Smad-1 immunoreactivity.

\section{DISCUSSION}

Dendritic growth can be induced in sympathetic neurons by coculture with glial cells or treatment with BMPs (Tropea et al., 1988; Lein et al., 1995; Guo et al., 1998). The following observations suggest a causal link between these phenomena. First, the spatiotemporal expression pattern of BMPs in SCG correlates with periods of dendritic growth in vivo. In SCG, 
dendritic growth begins prenatally, and maximal expansion of the dendritic arbor occurs during postnatal weeks 1 and 2 (Rubin, 1985; Voyvodic, 1987). Transcriptional and translational products for BMP5, -6 , and -7 were present at significant levels throughout the ganglia from E20 through PN7. Others have reported that transcripts for $\mathrm{BMP} 2,-5$, and -7 can be isolated from E14 sympathetic ganglia (Kobayashi et al., 1998). These data, together with observations that mRNA for BMP type IA and type II receptors are expressed in perinatal sympathetic ganglia (Zhang et al., 1998), are consistent with a role for BMPs in regulating the initiation and rapid expansion of the dendritic arbor in sympathetic ganglia.

BMP5, -6, and -7 were also detected in blots of cell lysates and conditioned medium from neuron-glia cocultures; in contrast, analyses using BMP2- or BMP4-specific antibodies yielded negative data. These data suggest that multiple members of the $60 \mathrm{~A}$ BMP subfamily are synthesized and secreted by neuron-glia cocultures. Immunocytochemical analyses of cocultures indicate that BMP5, -6, and -7 are localized to glial cells, but neurons also display significant immunoreactivity for these BMPs, raising the question of which cell type(s) actually synthesizes BMPs. Two lines of evidence indicate that both cell types are capable of transcribing and translating BMPs. First, as revealed by in situ hybridization, glia as well as neurons cultured in the presence or absence of glia express BMP6 and -7 transcripts at significant levels. Second, BMP5, -6 , and -7 proteins are detected by immunocytochemical and Western blot analyses in purified cultures of either cell type.

There are reports that mRNA for BMPs is detected in CNS neurons during development (Wall et al., 1993; Tomizawa et al., 1995). However, the observation that sympathetic neurons contain mRNA for BMP6 and -7 and are apparently capable of translating this mRNA and secreting the resultant protein product was unexpected because previous studies demonstrated that these neurons require exposure to either glia or exogenous BMPs to initiate dendritic growth (Tropea et al., 1988; Lein et al., 1995). There are at least two plausible explanations for these seemingly discrepant observations: (1) the addition of large numbers of glial cells to low-density cultures of sympathetic neurons increases BMPs to biologically active concentrations, an explanation that would be consistent with previous reports of weak dendritic growth in sympathetic neurons cultured at very high cell densities in the absence of glia (Bruckenstein and Higgins, 1988), and (2) coculture decreases levels of BMP antagonists. Our data suggest that both mechanisms may underlie glial-induced dendritic growth. Comparative Western blot analyses of BMP concentrations in neuron-glia cocultures versus purified neuronal populations indicate significant upregulation of BMP expression in the former. Increased BMP levels in neuron-glia cocultures may reflect specific upregulation of BMP7 synthesis mediated by neuron-glia interactions or simply an increased density of BMPexpressing cells in cocultures. Our data support the former interpretation in that an equal amount of protein was loaded into all lanes, and $\alpha$-tubulin levels did not differ across cell lysate samples. However, we cannot determine from these studies whether the increased BMP levels result from upregulated synthesis in glia or neurons, or both.

There is increasing evidence that BMP signaling in the developing nervous system is regulated not only by expression of BMPs and their receptors but also by soluble BMP antagonists (McMahon et al., 1998; Sela-Donenfeld and Kalcheim, 1999; Li and LoTurco, 2000; Smith and Graham, 2001). Tran- scripts for both noggin and follistatin were detected in intact SCG and in purified cultures of neurons. Coculture with glia had no appreciable effect on mRNA expression for these BMP antagonists. However, adding glia to neuronal cultures did significantly decrease levels of BMPs complexed to noggin and follistatin. Although these data do not directly demonstrate that coculture with glia decreases protein levels of these BMP antagonists, there are two reasons to suspect that this may be true. First, the volume of extract used for immunoprecipitation was adjusted such that equivalent amounts of protein were processed for each culture condition. Second, noggin and follistatin bind BMPs with greater affinity than BMP receptors (Holley et al., 1996; Zimmerman et al., 1996; Fainsod et al., 1997; Iemura et al., 1998), so it is unlikely that the extracellular compartment contains significant levels of antagonist not complexed to BMPs. The mechanism(s) by which glia cause downregulation of noggin and follistatin is not known. Furthermore, these observations stand in contrast to the current paradigm of a negative feedback loop in which BMPs induce expression of BMP antagonists (Gazzerro et al., 1998; Pereira et al., 2000). However, this paradigm was established using non-neural systems, principally osteoblasts, and other studies of the developing nervous system have demonstrated that paraxial mesoderm in the dorsal neural tube functions to downregulate noggin expression in the presence of physiologically active concentrations of BMPs (Sela-Donenfeld and Kalcheim, 2000).

On the basis of these data, we propose that glia induce dendritic growth in sympathetic neurons by increasing BMP activity via two mechanisms: (1) increased synthesis of BMPs and (2) decreased expression of noggin and follistatin. The most direct support for this hypothesis is the finding that glial-induced dendritic growth in cultured sympathetic neurons is significantly reduced by function-blocking BMP antibodies and completely blocked by the BMP antagonists noggin and follistatin. The observation that glial-induced dendritic growth is effectively blocked by three different agents that inhibit BMP activity via different molecular mechanisms suggests that their inhibitory effects result from a direct block of BMP function and not from nonspecific molecular interactions or crossreactivity. A potential difficulty with this interpretation is that follistatin is known to avidly bind not only BMPs but also activin (Nakamura et al., 1990). However, earlier studies have shown that neither activin nor other members of the TGF- $\beta$ superfamily such as GDNF, dorsalin, TGF- $\beta 1$, or $-\beta 2$, induce dendritic growth in sympathetic neurons (Lein et al., 1995), suggesting that dendrite-promoting activity is restricted to the BMP subfamily.

The data obtained from the function-blocking studies suggest that multiple BMPs mediate the dendrite-promoting activity of glia. Thus, BMP7 mAbs caused significant but not complete inhibition of dendritic growth. One explanation is that the BMP7 $\mathrm{mAbs}$ exhibit a 10-fold lower binding affinity for BMP7 relative to BMP7 receptors (P. Kaplan, unpublished observations). However, because $\mathrm{BMP} 2,-5$, and -6 have also been reported to promote dendritic growth in sympathetic neurons (Guo et al., 1998; Beck et al., 2001), an additional explanation is that neuronglia cocultures express multiple BMPs. This interpretation is consistent with observations that noggin and follistatin, which block multiple BMPs, cause a greater inhibition of glial-induced dendritic growth. Moreover, our immunocytochemical and Western blot analyses demonstrate that neuron-glia cocultures express mRNA and protein not only for BMP7 but also BMP5 and -6. 
One question not answered by the functional studies of the role of BMPs in dendritic growth is whether BMPs directly induce dendritic growth via interaction with neuronal receptors or indirectly via activation of glia to produce a dendrite-promoting stimulus. BMP binding to surface receptors causes translocation of the transcription factor Smad-1 from the cytoplasm to the nucleus. Analysis of the subcellular localization of Smad-1 immunoreactivity in neuron-glia cocultures indicated that $>70 \%$ of the neurons, but $<20 \%$ of the glia, exhibited nuclear Smad-1 staining. These data suggest that BMPs interact directly with neuronal receptors to induce dendritic growth. This interpretation is consistent with previous reports that addition of recombinant BMPs to purified cultures of neurons is sufficient to elicit robust dendritic growth (Lein et al., 1995; Guo et al., 1998).

Neuronal cell division predominates during the early formation of the SCG (E14.5-18.5), whereas glial cell populations begin dividing rapidly later in development and continue expanding in number in the postnatal ganglion (Hendry, 1977). Thus, we propose the following model. During the early formation of the SCG, neurons synthesize and secrete both BMPs and BMP antagonists, and the balance is such that the antagonists effectively inhibit the dendrite-promoting activity of the BMPs. However, as glial cell populations begin to proliferate, the levels of BMPs begin to increase, whereas the levels of BMP antagonists begin to decrease. Thus the balance is shifted such that BMP antagonists become saturated, and BMPs released from inhibition are able to activate neuronal receptors resulting in dendritic growth. Future work will be aimed at identifying the mechanism(s) by which neuron-glia interactions stimulates BMP synthesis and downregulates noggin and follistatin expression.

\section{REFERENCES}

Ai X, Cappuzzello J, Hall AK (1999) Activin and bone morphogenetic proteins induce calcitonin gene-related peptide in embryonic sensory neurons in vitro. Mol Cell Neurosci 14:506-518.

Barres BA (1999) A new role for glia: generation of neurons! Cell 97:667-670.

Beck HN, Drahushuk K, Jacoby DB, Higgins D, Lein PJ (2001) Bone morphogenetic protein-5 (BMP-5) promotes dendritic growth in cultured sympathetic neurons. BMC Neurosci 2:12.

Bruckenstein DA, Higgins D (1988) Morphological differentiation of embryonic rat sympathetic neurons in tissue culture. I. Conditions under which neurons form axons but not dendrites. Dev Biol 128:324-336.

Calvet S, Doherty P, Prochiantz A (1998) Identification of a signaling pathway activated specifically in the somatodendritic compartment by a heparan sulfate that regulates dendrite growth. J Neurosci 18:9751-9765.

Cho KW, Blitz IL (1998) BMPs, Smads and metalloproteases: extracellular and intracellular modes of negative regulation. Curr Opin Genet Dev 8:443-449.

Fainsod A, Deissler K, Yelin R, Marom K, Epstein M, Pillemer G, Steinbeisser H, Blum M (1997) The dorsalizing and neural inducing gene follistatin is an antagonist of BMP-4. Mech Dev 63:39-50.

Gazzerro E, Gangji V, Canalis E (1998) Bone morphogenetic proteins induce the expression of noggin, which limits their activity in cultured rat osteoblasts. J Clin Invest 102:2106-2114.

Gratacos E, Checa N, Alberch J (2001) Bone morphogenetic protein-2, but not bone morphogenetic protein-7, promotes dendritic growth and calbindin phenotype in cultured rat striatal neurons. Neuroscience 104:783-790.

Guo X, Rueger D, Higgins D (1998) Osteogenic protein-1 and related bone morphogenetic proteins regulate dendritic growth and the expression of microtubule-associated protein-2 in rat sympathetic neurons. Neurosci Lett 245:131-134.

Guo X, Lin Y, Horbinski C, Drahushuk KM, Kim IJ, Kaplan PL, Lein P, Wang T, Higgins D (2001) Dendritic growth induced by BMP-7 requires Smad1 and proteasome activity. J Neurobiol 48:120-130.

Hatten ME (1990) Riding the glial monorail: a common mechanism for glial-guided neuronal migration in different regions of the developing mammalian brain. Trends Neurosci 13:179-184.
Hendry IA (1977) Cell division in the developing sympathetic nervous system. J Neurocytol 6:299-309.

Higgins D, Lein P, Osterhout D, Johnson MI (1991) Tissue culture of autonomic neurons. In: Culturing nerve cells, Ed 1 (Banker G, Goslin K, eds), pp 177-205. Cambridge, MA: MIT.

Higgins D, Burack M, Lein P, Banker G (1997) Mechanisms of neuronal polarity. Curr Opin Neurobiol 7:599-604.

Holley SA, Neul JL, Attisano L, Wrana JL, Sasai Y, O'Connor MB, De Robertis EM, Ferguson EL (1996) The Xenopus dorsalizing factor noggin ventralizes Drosophila embryos by preventing DPP from activating its receptor. Cell 86:607-617.

Jones BW, Fetter RD, Tear G, Goodman CS (1995) Glial cells missing: a genetic switch that controls glial versus neuronal fate. Cell 82:10131023.

Jordan J, Bottner M, Schluesener HJ, Unsicker K, Krieglstein K (1997) Bone morphogenetic proteins: neurotrophic roles for midbrain dopaminergic neurons and implications of astroglial cells. Eur J Neurosci 9:1699-1709.

Kobayashi M, Fujii M, Kurihara K, Matsuoka I (1998) Bone morphogenetic protein-2 and retinoic acid induce neurotrophin-3 responsiveness in developing rat sympathetic neurons. Brain Res Mol Brain Res 53:206-217.

Lamb TM, Knecht AK, Smith WC, Stachel SE, Economides AN, Stahl N, Yancopolous GD, Harland RM (1993) Neural induction by the secreted polypeptide noggin. Science 262:713-718.

Lein P, Johnson M, Guo X, Rueger D, Higgins D (1995) Osteogenic protein-1 induces dendritic growth in rat sympathetic neurons. Neuron 15:597-605.

Lein P, Drahushak KM, Higgins D (2002) Effects of bone morphogenetic proteins on neural tissue. In: Bone morphogenetic proteins: from laboratory to clinical practice (Vukicevic S, Sampath KT, eds), pp 289-319. Basel: Birkhauser Verlag.

Le Roux P, Behar S, Higgins D, Charette M (1999) OP-1 enhances dendritic growth from cerebral cortical neurons in vitro. Exp Neurol 160:151-163.

Li W, LoTurco JJ (2000) Noggin is a negative regulator of neuronal differentiation in developing neocortex. Dev Neurosci 22:68-73.

Lim DA, Tramontin AD, Trevejo JM, Herrera DG, Garcia-Verdugo JM, Alvarez-Buylia A (2000) Noggin antagonizes BMP signaling to create a niche for adult neurogenesis. Neuron 28:713-726.

McMahon JA, Takada S, Zimmerman LB, Fan CM, Harland RM, McMahon AP (1998) Noggin-mediated antagonism of BMP signaling is required for growth and patterning of the neural tube and somite. Genes Dev 12:1438-1452.

Nakamura T, Takio K, Eto Y, Shibai H, Titani K, Sugino H (1990) Activin-binding protein from rat ovary is follistatin. Science 247:836-838.

Ozkaynak E, Schnegelsberg PN, Jin DF, Clifford GM, Warren FD, Drier EA, Oppermann H (1992) Osteogenic protein-2. A new member of the transforming growth factor-beta superfamily expressed early in embryogenesis. J Biol Chem 267:25220-25227.

Pereira RC, Economides AN, Canalis E (2000) Bone morphogenetic proteins induce gremlin, a protein that limits their activity in osteoblasts. Endocrinology 141:4558-4563.

Pfrieger FW, Barres BA (1996) New views on synapse-glia interactions. Curr Opin Neurobiol 6:615-621.

Rubin E (1985) Development of the rat superior cervical ganglion: ganglion cell maturation. J Neurosci 5:673-684.

Schluesener HJ, Meyermann R (1994) Expression of BMP-6, a TGF-beta related morphogenetic cytokine, in rat radial glial cells. Glia 12:161-164.

Schluesener HJ, Meyermann R, Jung S (1995) Immunolocalization of vgr (BMP-6, DVR-6), a TGF-beta related cytokine, to Schwann cells of the rat peripheral nervous system: expression patterns are not modulated by autoimmune disease. Glia 13:75-78.

Sela-Donenfeld D, Kalcheim C (1999) Regulation of the onset of neural crest migration by coordinated activity of BMP4 and Noggin in the dorsal neural tube. Development 126:4749-4762.

Sela-Donenfeld D, Kalcheim C (2000) Inhibition of noggin expression in the dorsal neural tube by somitogenesis: a mechanism for coordinating the timing of neural crest emigration. Development 127:4845-4854.

Smith A, Graham A (2001) Restricting Bmp-4 mediated apoptosis in hindbrain neural crest. Dev Dyn 220:276-283.

Tiedge H (1991) The use of UV light as a cross-linking agent for cells and tissue sections in in situ hybridization. DNA Cell Biol 10:143-147.

Tomizawa K, Matsui H, Kondo E, Miyamoto K, Tokuda M, Itano T, Nagahata S, Akagi T, Hatase O (1995) Developmental alteration and neuron-specific expression of bone morphogenetic protein-6 (BMP-6) mRNA in rodent brain. Brain Res Mol Brain Res 28:122-128.

Tropea M, Johnson MI, Higgins D (1988) Glial cells promote dendritic development in rat sympathetic neurons in vitro. Glia 1:380-392.

Vaillant C, Didier-Bazes M, Hutter A, Belin MF, Thomasset N (1999) Spatiotemporal expression patterns of metalloproteinases and their inhibitors in the postnatal developing rat cerebellum. J Neurosci 19: 4994-5004. 
Vaughan PJ, Pike CJ, Cotman CW, Cunningham DD (1995) Thrombin receptor activation protects neurons and astrocytes from cell death produced by environmental insults. J Neurosci 15:5389-5401.

Voyvodic JT (1987) Development and regulation of dendrites in the rat superior cervical ganglion. J Neurosci 7:904-912.

Vukicevic S, Latin V, Chen P, Batorsky R, Reddi AH, Sampath TK (1994) Localization of osteogenic protein-1 (bone morphogenetic protein-7) during human embryonic development: high affinity binding to basement membranes. Biochem Biophys Res Commun 198:693-700.

Wall NA, Blessing M, Wright CV, Hogan BL (1993) Biosynthesis and in vivo localization of the decapentaplegic-Vg-related protein, DVR-6 (bone morphogenetic protein-6). J Cell Biol 120:493-502.
Withers GS, Higgins D, Charette M, Banker G (2000) Bone morphogenetic protein-7 enhances dendritic growth and receptivity to innervation in cultured hippocampal neurons. Eur J Neurosci 12:106-116.

Zhai Y, Higgins D, Napoli JL (1997) Coexpression of the mRNAs encoding retinol dehydrogenase isozymes and cellular retinol-binding protein. J Cell Physiol 173:36-43.

Zhang D, Mehler MF, Song Q, Kessler JA (1998) Development of bone morphogenetic protein receptors in the nervous system and possible roles in regulating trkC expression. J Neurosci 18:3314-3326.

Zimmerman LB, De Jesus-Escobar JM, Harland RM (1996) The Spemann organizer signal noggin binds and inactivates bone morphogenetic protein 4. Cell 86:599-606. 